\title{
Inmunofenotipo de leucemias agudas del Hospital Nacional Dos de Mayo, durante el periodo 2011-julio 2012
}

\author{
Oscar Ruiz, Carla Moore, John Rojas, David Díaz, Carlos Peña, Manuela Marangoni, \\ Carlos Delgado \\ Instituto de Investigaciones Clínicas, Facultad de Medicina, UNMSM, y Hospital Nacional Dos de Mayo
}

Objetivos: Determinar la prevalencia de leucemias agudas, por inmunofenotipo.

Diseño: Descriptivo transversal.

Institución: Instituto de Investigaciones Clínicas, Facultad de Medicina, UNMSM, y Hospital Nacional Dos de Mayo (HNDM). Participantes: Pacientes con neoplasias hematológicas atendidos en el HNDM en el periodo 2011-julio 2012.

Intervenciones: A todos los pacientes se realizó hemograma, mielograma, citometría de flujo (sangre medular).

Principales medidas de resultados: Prevalencia de neoplasias hematológicas y leucemias agudas, características inmunofenotípicas.

Resultados: Se encontró 80 neoplasias hematológicas: 42 (52,5\%) leucemias agudas, 21(26,3\%) mieloma múltiple, 8 $(10 \%)$, linfomas, $5(6,3 \%)$ sindromes mieloproliferativos crónicos, $4(5 \%)$ mielodisplasias. Las leucemias agudas con citometría, en $12(41,4 \%)$ mujeres y $17(58,6 \%)$ varones se encontró lla $17(40,5 \%), 12(28,6 \%)$ Ima, $13(30,9 \%)$ no tipificada. Características inmunofenotipicas de las lla: 2 fueron t y 15 b. Orden de frecuencia: lla común pura (10), lla pre b (02), lla pro b (02) lla bifenotípica (01). En Ima: (12) Ima-m2 (08), Ima-mo (1), Ima-m1 (1), Ima-m3 (1), Ima-m5 (1).

Conclusiones: $52 \%$ de las neoplasias en el HNDM fueron leucemias agudas. La lla b común fue la más frecuente ( $58,8 \%$ respecto a lla y $34,5 \%$ a todas las leucemias agudas con citometría), prevalencia similar a otros estudios internacionales.

Palabras clave: Leucemia aguda, inmunofenotipo.

\section{Estandarización de una prueba de Elisa para detectar anticuerpos IgE en pacientes con equinococosis quística y su utilidad en el diagnóstico y seguimiento de pacientes tratados con albendazol: reporte preliminar}

\author{
Herman Vildózola, Yrma Espinoza, William Roldán \\ Instituto de Medicina Tropical Daniel A. Carrión, Facultad de Medicina, UNMSM
}

Objetivos: Determinar niveles de Elisa anti-lgE, sensibilidad, especificidad y valor predictivo en pacientes con equinococosis quística. Demostrar la correlación entre los niveles de lgE específicos con la respuesta al tratamiento médico con albendazol.

Diseño: Estudio cuasiexperimental con grupo control para la prueba de Elisa IgE y preexperimento con preprueba y posprueba en un solo grupo, para diagnóstico y seguimiento postratamiento.

Institución: Instituto de Medicina Tropical Daniel A. Carrión, Facultad de Medicina, UNMSM.

Participantes: Pacientes sanos y con equinococosis quística y otras helmintiasis.

Intervenciones: Para Elisa, se utilizó suero de 5 pacientes con equinococosis quística; para sensibilidad y especificidad el suero de 30 pacientes sanos. Para reacciones cruzadas, 16 pacientes con otras helmintiasis y para el diagnóstico y seguimiento postratamiento, el suero de 17 pacientes.

Principales medidas de resultados: Sensibilidad y especificidad para Elisa y porcentajes de positividad para el diagnóstico y seguimiento.

Resultados: Elisa IgE; sensibilidad de 95,6\% y especificidad de 100\%. En quiste hidatídico hepático curados, disminuyeron los niveles de IgE hasta la negativización. Elevación de los niveles en la recurrencia de enfermedad quística hepática.

Conclusiones: Elisa IgE tuvo 95,6\% sensibilidad y 100\% especificidad en equinococosis quística. La curación coincidió con una disminución progresiva de IgE hasta negativizarse un año postratamiento y elevarse en la recurrencia. Persistencia de niveles elevados de IgE cuando no hubo respuesta.

Palabras clave: Elisa IgE, equinococosis quística, albendazol. 